the order of civilization is to crumble away, it is not discussion of general principles or machinery, in other words of the form of government and the means to secure it, which will save mankind from disaster, but the scientific study on a co-operative basis of the concrete problems which are vital to the well-being and the very existence of the unit from which the social aggregation is built up, whatever its form-the individual man, woman and child.

\title{
THE NATIONAL REGISTER
}

A NATIONAL REGISTER is, in essence, a continuous census. It is best regarded as a means of obtaining and recording that accurate knowledge of its human resources which the advance of science has made necessary to a civilized community. For more than a century past a periodic census has given us a record, at approximately ten-year intervals, of the numbers and distribution of the population in Great Britain, together with varying amounts of information about its composition as to sex, age, occupations, and so on. These records have become fuller during that time; and there has been pressure to make them also more frequent. A quinquennial census has been authorized, though not carried out. Now, under the stress of war, we have begun the transition from a periodic to a continuous record. Of course, it is not possible to publish continuously; but it should be possible to issue quarterly returns, akin to those now submitted by the registrars-general in respect to births, deaths, and marriages.

The information collected for this first edition of a British National Register is similar to, though less extensive than, that for recent censuses. It is limited to the name, sex, age, condition as to marriage, and occupation of every individual, with an additional column for members of the defence services. The plans for it were made during peace but are being carried out in a country at war, which is probably the reason for the extreme reduction of the form to be filled in by each householder. The most striking omissions are the absence of questions as to nationality, birthplace, workplace, or usual residence for those away from home. The first of these may perhaps be adequately replaced by the register of aliens kept by the police; the others are less urgent at present. But all these, and more, will be needed for a permanent national register.

The new feature which distinguishes this registration from all previous censuses is the provision for keeping it up to date. This takes the form of a legal obligation placed on all persons to notify every change of residence to the National Registration Officer of the district into which they move. Soon this must be extended to notification of all changes that affect the Register, and are not otherwise recorded, such as a change of occupation. The records of all these changes will make it possible to obtain information of increase or decrease of population in every local government district at frequent intervals. Everyone concerned with the administration of local government, or of education, has often felt the need for such information, which will now become available in respect of all the people. It has hitherto been available only in respect of certain groups, such as those on the live registers of the employment exchanges. It is urgently needed by all authorities responsible for public health. For all such services, and for local transport and retail distribution, a National Register will make possible greater efficiency, providing that it is well maintained.

The last full census was taken in 1931. It is, therefore, out of date for many purposes. The need for a prompt stocktaking of all our manpower is now urgent; and the experience of the War of 1914-18 shows that some such register can be invaluable in respect to both military and industrial organization for war and to the maintenance of the national life. By its regimentation and conscription of men and women, the German Reich has already got some corresponding record of its human resources. Not enough is known here about the system used to allow useful com. parisons with this British register.

It is unfortunate that the Register was not compiled months ago, before the outbreak of war made the task at once more urgent and more difficult. The evacuation of children and women from large towns, and the parallel removal of many other people will make the early months of the war a time of special difficulty in keeping in touch with the abnormal number of changes of residence. On the other hand, the fact that the Register is to 
form the basis for the lists of those entitled to food ration cards provides a strong incentive to prompt notification. Even so, the organization for the maintenance of the Register will be very severely tested in the next few months.

This registration is accompanied by the introduction of the personal identity card, which has long been a familiar thing in many European countries, where its value has been well proved. Like the Register, this first identity card is extremely simplified: in fact it is scarcely more than a reference to the register by name and number. But both should become permanent features of our national life ; and both will inevitably become more comprehensive. The value of the card is obvious. In normal times, cases of difficulty in the identification of persons suffering from loss of memory, or victims of street accidents, are sufficiently frequent to stress the need for such a document. Only the law-breaker has a real, if not a socially valid, rcason for objecting to it. It is interesting to note that it does not bear the name of the country, thus following the tradition of British postage stamps.

The National Register and the identity card are essential to the scientific organization of a civilized community, and should have been introduced years ago. The State which does not know its human resources accurately cannot organize them well ; nor can it measure with sufficient accuracy its liabilities to its dependent members and its children. The rapidly increasing complexity of modern life, and the resultant increase in the number, the importance, and the intricacy of the functions of government, national and local, and of other social organizations, make it more and more necessary that their working shall be based on a full and accurate knowledge of our human resources and liabilities. For defence against external enemies, against disease, and against internal disorder, for the supply of satisfactory nutrition to all the population, in fact for all the many needs of social life for which we, as social beings, are dependent on the society of which we are units, it is necessary to have such knowledge as a national register can best provide. Each one of us is, willy-nilly, in some degree his brother's keeper and is affected by that brother's well-being or misfortune, and for the fulfilment of the social duties implied in this relation we need this know. ledge.

Of course this does not mean that the mere existence of a national register, however com. plete and well kept it may be, will ensure social efficiency. Nor can it determine any policy. It may be a basis for the development and application of policies of very different types and aims. It is only a tool, a very valuable tool, for the organization of life in a civilized country. How, and for what purposes, such a tool may or will be used is a matter of national policy that will be determined in the same way as other such policies are decided in Great Britain.

As an example of the matters on which precise information can be obtained from the Register as it is now, we may note the composition of the population, nationally and locally, by age and sex groups. It will be possible to know promptly if, and how far, internal movements such as the so-called 'drift to the south' have left some areas with an unduly low proportion of adolescents and young adults, and a correspondingly high proportion of either or both children and old people, and given to the areas of immigration a badly balanced population of reverse type. Many other examples of such possibilities could be given; but this one is enough to emphasize the value of the Register in enabling us to have accurate information of such social facts in place of uncertain estimates, which have hitherto been checked only by the periodic census.

This is the first attempt at compiling a national register in Great Britain; and, although it has been carefully planned, it is experimental. There can be no doubt that experience of its working will give rise to many suggestions for improvements and extensions intended to make it more useful. After the war, at least one census will be needed as a check on its accuracy, and to strengthen the continuity of our national records by an overlap between the periodic censuses and the continuous register. There will also be changes in the identity card and the record on it. Some day the official mind may grasp the fact that it would be a convenience to the public if such things as this card, driving licences, bank notes, postage stamp books, and other articles to be carried in a man's pocket or a lady's handbag, were made of standard uniform sizes.

The most valuable of all our national resources is the human material. The National Register can help to provide a more scientific basis for attempts to improve its quality, by nutrition and training, to control its numbers, and to make better use of it in the development of the good life for all members of our society. 